\title{
Flow characteristics of paste slurry under low atmospheric pressure in high altitude areas
}

\author{
Lei Zhang University of Science and Technology Beijing, China \\ Hongjiang Wang University of Science and Technology Beijing, China \\ Jiandong Wang University of Science and Technology Beijing, China \\ Junfei Zhang University of Science and Technology Beijing, China
}

Huixi Sun University of Science and Technology Beijing, China

\begin{abstract}
This paper establishes a relationship model between low atmospheric pressure and flow characteristics under high altitude conditions based on the theory of viscous fluid mechanics. It analyses and demonstrates that the plastic viscosity of the paste slurry is influenced by changes of atmospheric pressure. An orthogonal experiment is designed using an inclined pipe and measuring the corresponding rheological parameters in Beijing and Lhasa, respectively. Results show that low atmospheric pressure has little effect on the yield stress of the paste slurry, but has certain impact on the plastic viscosity of the slurry.
\end{abstract}

\section{Introduction}

As one of the key technologies in cemented filling, the design of the pipeline transport system determines the stable operation of the filling system (Huang and Sun, 2003). Compared with the simple two-phase flow with low concentration, unclassified tailings paste has obvious non-Newtonian characteristics as it flows in pipes (Belem and Benzaazoua, 2008). Studies (Wang et al., 2015; Gillies et al., 2007; Belem and Benzaazoua, 2004) have shown that the flow of paste slurry presents a stable state like the plug flow, which can be characterized by the Bingham model or the Herschel-Bulkley model. By fully studying the flow characteristics of paste slurry, the complexity of paste filling pipeline, pressure distribution and consumption imbalance are considered (Liu, 2001), which provides the technical basis for the operation of filling transport system and maintenance (Wang, 2010). However, in mines of high altitude, the flow characteristics of paste during filling slurry preparation and paste transport can be affected by factors including the different temperature sources (Nasir and Fall, 2009; Rawlins and Phillips, 2001) and low atmospheric pressure. It is not clear how low atmospheric pressure influences the flow characteristics of the paste slurry as research in this area is rarely reported. In other areas, Bair and Winer (1990) has examined the flow characteristics of viscous lubricant with the pressure increasing, but they has not conducted the experiment under low pressure conditions. Meanwhile, the flow characteristics of viscous lubricant as a type of Newton body are not suitable for the Bingham model of the paste. Therefore, it is essential to study the mechanism of the flow characteristics of the paste so as to provide theoretical and practical guidance for the transport stability of paste slurry pipelines in high altitude mines. 
Rheological parameters are an important index for evaluating the flow characteristics of paste slurry. A number of studies on the rheological properties of filling slurry (Liu et al., 2014; Wang et al., 2008; Wang et al., 2004; Wallevik, 2009) have mainly used the direct or the indirect method. The direct method uses various types of rheometer, such as the paddle type rheometer (e.g. the R/S +SST rheometer and the NXS-11A rotational viscometer), the concentric cylinder rheometer (Wang et al., 2010) and the parallel plate rheometer (Berrich et al., 2011). Using this method, the rheological parameters, such as yield stress and viscosity, can be conveniently obtained (Wu et al., 2013). However, the measured data are not stable and exhibit a large deviation, especially when some coarse aggregates are added (Dzuy and Boger, 1983). Based on the assumptions of the fluid model, the indirect method, on the other hand, obtains the corresponding rheological parameters by fitting the data of the loop test (Karasua et al., 2015). Although most well adapted to practical field conditions, it is not widely used because of the complexity of the experimental device and great labor intensity (Clark et al., 1995). In view of the disadvantages of the rheometer and the loop test device, the inclined pipe device was designed in order for a simply and convenient determination of rheological parameters.

In accordance with the safety supervision of high altitude and high concentration filling of a copper mine in Lhasa, China, the relationship model between the low atmospheric pressure of high altitude conditions and the flow characteristics was established on the basis of the theory of viscous fluid mechanics.

The analysis demonstrated that low atmospheric pressure influenced the flow characteristics of paste slurry by changing its plastic viscosity. The effect of low pressure conditions on the rheological parameters of paste slurry was analyzed with the experimental data, hence providing guidance for the stable operation of high altitude paste filling system.

\section{Theory regarding flow characteristics of paste slurry under low atmospheric pressure}

In order to simplify the model, paste slurry can be regarded as a non-compressible viscous fluid that flows with continuous and constant velocity in the inclined pipe. Because of the influence of the slurry viscosity and the roughness of the pipe wall, flow resistance is formed, exerting a negative effect on the slurry. The roughness of the pipe wall can consume the mechanical energy of the system (Meng, 2011). Thus, the kinetic formula can be expressed in Equation (1):

$$
\Delta E=\sum W=W_{G}+W_{P}-W_{f}
$$

Where:

$$
\begin{aligned}
& W_{G}=\text { Work of gravity; } \\
& W_{P}=\text { That of pressure; } \\
& W_{f}=\text { That of friction; }
\end{aligned}
$$

Figure 1 shows a paste slurry element in the flowing process. Select 1 and 2 sections and flow sections are $d_{A 1}$ and $d_{A 2}$ respectively. The height of the two sections is $Z_{1}$ and $Z_{2}$ respectively from the baseline 0-0. The flow rates of the slurry in two sections are $v_{1}$ and $v_{2}$, respectively, and the pressures are respectively $P_{1}$ and $P_{2}$. 


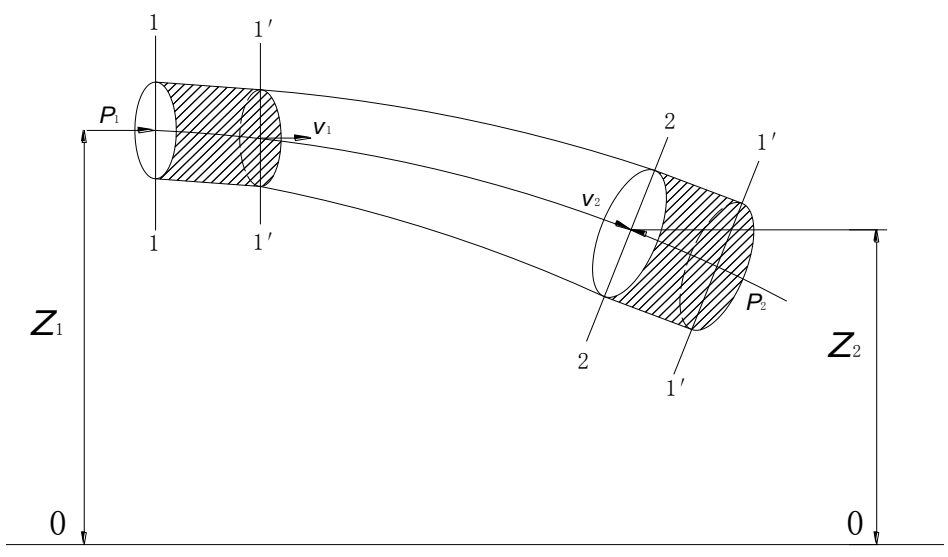

\section{Figure 1 Flow diagram of viscous fluid element}

By analysing the infinitesimal, the kinetic energy variation is:

$$
\Delta E=\frac{1}{2} d m u_{2}^{2}-\frac{1}{2} d m u_{1}^{2}=\rho g d Q d t\left(\frac{u_{2}^{2}}{2 g}-\frac{u_{1}^{2}}{2 g}\right)
$$

The pressure exerted on the element flow consists of that on the two cross sections and that on the side. But as it is perpendicular to the flow direction of the element, the positive pressure on the side does not work. Therefore, the work of pressure can be expressed as:

$$
W_{P}=P_{1} d A_{1} u_{1} d t-P_{2} d A_{2} u_{2} d t=\left(P_{1}-P_{2}\right) d Q d t
$$

The work of gravity of the element flow is the potential difference between 1-1'and 2-2':

$$
W_{G}=\rho g d Q d t\left(Z_{1}-Z_{2}\right)
$$

So the kinetic formula can be expressed as:

$$
\rho g d Q d t\left(\frac{u_{2}^{2}}{2 g}-\frac{u_{1}^{2}}{2 g}\right)=\rho g d Q d t\left(Z_{1}-Z_{2}\right)+\left(P_{1}-P_{2}\right) d Q d t-W_{f}
$$

Let $W_{f} /(\rho g \cdot d Q \cdot d t)=h_{f}$, and both sides of the equation are divided by $d t, \rho g$ and $d Q$ :

$$
u_{2}^{2}-u_{1}^{2}=2 g\left[\left(Z_{1}-Z_{2}\right)+h_{f}\right]+\frac{P_{1}-P_{2}}{2 \rho}
$$

According to Equation (6), the constant difference of $\left(u_{2}^{2}-u_{1}^{2}\right)$ is constant under the ideal flow state; $Z_{1}-Z_{2}, \rho$ and $g$ remain unchanged under the same experimental conditions in Lhasa and Beijing. Although the atmospheric pressure of high altitude areas is not consistent with that of the plain areas, the pipeline device is in full contact with the external environment, making $P_{1}-P_{2}$ remain changed. The right-hand side of Equation (6) shows that only the change of $h_{f}$ affects the flow rate difference, which cannot be ignored because of the change of the paste slurry flow.

Combining the formula of the resistance loss in the circular tube with the expression of the Reynolds number:

$$
h_{f}=\frac{32 v \mu l}{\rho g d^{2}}
$$

Where:

$$
\begin{array}{ll}
\mu & =\text { Slurry viscosity } \\
\rho & =\text { Density of the slurry } \\
v & =\text { Average velocity } \\
l & =\text { Pipe length; }
\end{array}
$$


As is shown in Equation (7), when other conditions remain unchanged, changes in the viscosity of the paste slurry will change the resistance loss along the way, thus affecting the flow characteristics of the paste slurry. Therefore, the relationship between the atmospheric pressure and flow characteristics of the paste slurry can be established, with the plastic viscosity of the paste bringing the two together. If low atmospheric pressure can change the plastic viscosity of the paste slurry, the flow characteristics of the paste will change accordingly. Hirai and Eyring (1959) have put forward the relationship between the viscosity of the viscous fluid and the pressure exerted by the external environment:

$$
\eta_{P}=\eta_{P_{0}} \exp \left[\beta\left(P-P_{0}\right)\right]
$$

Where:

$\eta_{p} \quad=$ Fluid viscosity under the condition of external pressure $P$;

$\eta_{P_{0}}=$ Fluid viscosity under the normal condition of external pressure $P_{0}$;

$\beta=$ Pressure coefficient;

The pressure coefficient $\beta$ is related to the porosity of solid materials $\left(V_{H}\right)$ and the absolute temperature $(T)$ :

$$
\beta=\frac{V_{H}}{R T}
$$

Where:

$$
\begin{aligned}
& \mathrm{R}=\text { General air constant; } \\
& T=\text { Absolute temperature constant; }
\end{aligned}
$$

It can be found from Equations (8) and (9) that plastic viscosity of the paste increases with the decrease of atmospheric pressure, so the resistance loss of the paste slurry flow in high altitude areas is greater than that in the plain areas because of low atmospheric pressure under the same experimental conditions. It can be concluded that the flow characteristics of the paste slurry in high altitude areas is lower than that in the plain areas.

\section{$3 \quad$ Materials and methods}

\subsection{Experimental materials}

The experimental materials include unclassified tailings and cement. The unclassified tailings were obtained from a copper mine located in Lhasa, Tibet, China. The content of fine particles smaller than $20 \mu \mathrm{m}$ is $32.4 \%$ and that of fine particles smaller than $70 \mu \mathrm{m}$ is $56.8 \%$. The content of average particle size is $58.74 \mu \mathrm{m}$. The binder is ordinary Portland cement. The physical quantity test of the unclassified tailings is shown in Table.

Table 1 Physical and mechanical parameters of tailings

\begin{tabular}{cccccc}
\hline $\begin{array}{c}\text { Proportion } \\
(\mathrm{kg} / \mathrm{m})\end{array}$ & $\begin{array}{c}\text { Loose bulk density } \\
(\mathrm{k} / \mathrm{m})\end{array}$ & $\begin{array}{c}\text { Dense bulk } \\
\text { density }(\mathrm{kg} / \mathrm{m})\end{array}$ & $\begin{array}{c}\text { Loose porosity } \\
(\%)\end{array}$ & $\begin{array}{c}\text { Density } \\
\text { porosity }(\%)\end{array}$ & $\begin{array}{c}\text { Water content } \\
(\%)\end{array}$ \\
\hline 3138 & 1549 & 1976 & 51.40 & 36.80 & 0.21 \\
\hline
\end{tabular}

\subsection{Apparatus}

The experimental device includes a circular tube, a feeding hopper, a feeding trough, a bracket, and so on. The device is shown in Figure 2. 


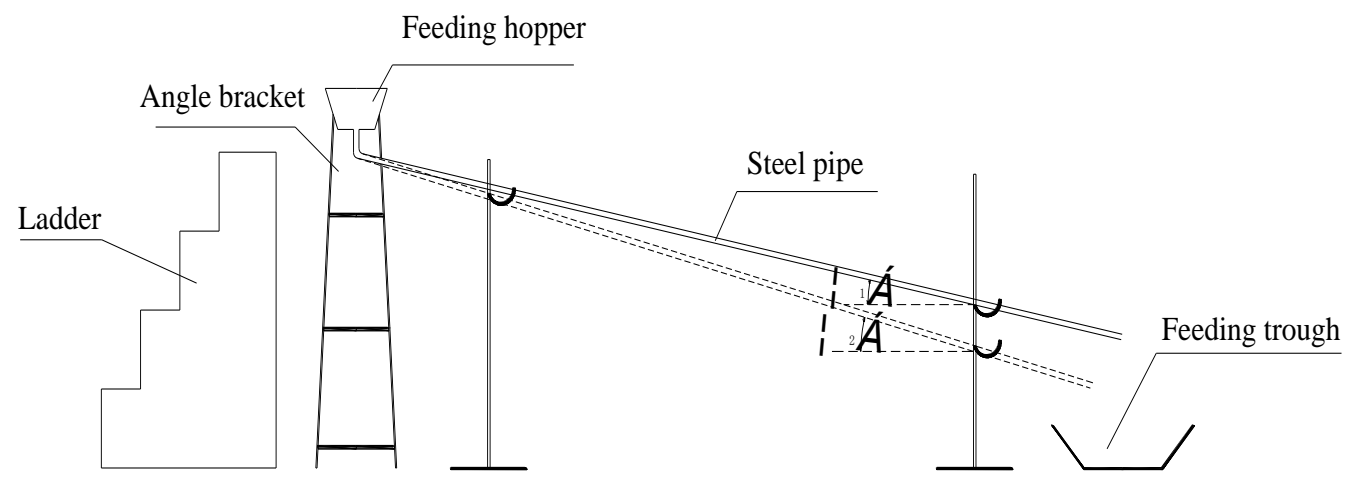

\section{Figure 2 Inclined pipeline test device}

The even paste slurry was poured into the feeding hopper and the angle of the inclined pipe was designed to between 8.5 and $11.5^{\circ}$ to simulate the filling rate to the maximum extent.

\subsection{Experimental principle}

The force analysis of the paste slurry in the pipe is presented in Figure 3.

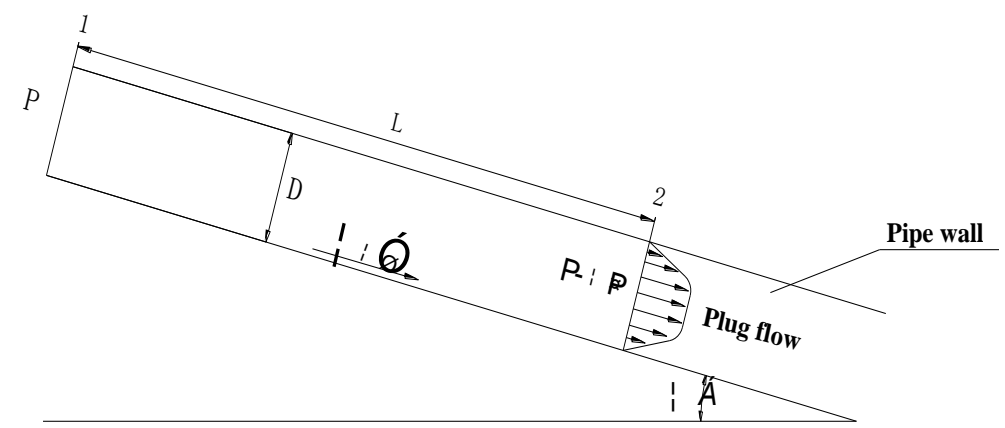

Figure 3 Force analysis of slurry unit in the pipe

When the high concentration slurry flows in the inclined pipe, and the force balance equation is:

$$
\tau_{w}=\frac{\Delta P \cdot D}{4 L}+\frac{D \rho g \sin \alpha}{4}
$$

Where:

$$
\begin{array}{ll}
\tau_{w} & =\text { Shear stress of the slurry on the pipe wall; } \\
D & =\text { Pipe diameter; } \\
\mathrm{L} & =\text { Length of the infinitesimal body of the slurry; } \\
\alpha & =\text { Pipe inclination angle; } \\
\Delta P & =\text { Pressure at both sections of the slurry; } \\
\rho & =\text { Density of the slurry; } \\
g & =\text { Acceleration of gravity; }
\end{array}
$$

In the Bingham fluid model, the relationship between the shear stress $\tau_{w}$ on the pipe wall and the shear rate $8 v / D$ can be expressed by the Buckingham formula. Generally, in structural flow areas, the relationship between $\tau_{w}$ and $8 v / D$ is linear in the range of high shear rate. Therefore, the Buckingham formula can be expressed as: 


$$
\tau_{w}=\frac{4}{3} \tau_{0}+\frac{8 v}{D} \mu_{B}
$$

Where:

$$
\begin{array}{ll}
\tau_{0} & =\text { Yield stress; } \\
\mu_{B} & =\text { Plastic viscosity; } \\
v & =\text { Velocity }
\end{array}
$$

According to the Bernoulli formula and the Darcy-Weisbach formula (Hogarth et al., 2005):

$$
h=\frac{\Delta P}{\rho g}+\frac{v^{2}}{2 g}+\lambda \frac{L}{D} \cdot \frac{v^{2}}{2 g}
$$

Where:

$h \quad=$ Height difference between the inlet and outlet of the inclined pipe and $h=L \sin \alpha$;

$v \quad=$ Average velocity of the slurry;

$h_{w}=$ Resistance loss of the pipeline along the path;

Combine Equations (11) and (12) and put them into Equation (10):

$$
\frac{4}{3} \tau_{0}+\mu_{B} \cdot \frac{8 v}{D}=\frac{\rho D}{4 L}\left(g\left(h-h_{w}\right)-\frac{v^{2}}{2}\right)+\frac{\rho D g \sin \alpha}{4}
$$

\subsection{Experimental methods}

For the inclined pipe experimental device, $D$ and $L$ are known quantifications and $g$ is the constant value in spite of the altitude differences in the Beijing and Lhasa. $\rho$ can be determined by the paste slurry and the corresponding $h_{w}$ can be calculated by Equation (12). After the inclination angle of the device has been adjusted, the flow rate of the paste slurry is determined. Hence, a binary linear equation under the condition of two different inclinations can be obtained.

$$
\left\{\begin{array}{l}
\frac{4}{3} \tau_{0}+\frac{8 v_{1}}{D} \mu_{B}=\rho D\left(\frac{g \sin \alpha_{1}}{2}-\frac{v_{1}{ }^{2}}{8 L}-\frac{g h_{w 1}}{4 L}\right) \\
\frac{4}{3} \tau_{0}+\frac{8 v_{2}}{D} \mu_{B}=\rho D\left(\frac{g \sin \alpha_{2}}{2}-\frac{v_{2}{ }^{2}}{8 L}-\frac{g h_{w 2}}{4 L}\right)
\end{array}\right\}
$$

The paste slurry is poured into the feeding hopper and the constant level of the liquid at the beginning of the flow experiment is controlled to stabilize the flow rate. In order to ensure the accuracy of the experiment, the flow time should be more than $10 \mathrm{~s}$.

The flow rate is determined by blocking the outlet pipe with the ball valve under the fixed angle and pouring the paste slurry into the feeding hopper. The ball valve is released in order to keep the slurry at an even level to calculate its velocity. Recording the flowing time $t$ and mass of the slurry $m$, the flow rate $v$ is:

$$
v=\frac{4 m}{\rho \pi \cdot d^{2} t}
$$

Where:

$$
\begin{array}{ll}
\rho & =\text { Slurry density; } \\
d & =\text { Pipeline diameter; }
\end{array}
$$

As shown in Table 2, the experiment of two factors and five levels was conducted by controlling the mass fraction of the slurry and the cement-sand ratio. 
Table 2 Experimental scheme

\begin{tabular}{ccc}
\hline Level & Cement-sand ratio & Mass fraction (\%) \\
\hline 1 & $1: 4$ & 70 \\
2 & $1: 6$ & 72 \\
3 & $1: 25$ & 74 \\
4 & $1: 8$ & 76 \\
5 & $1: 12$ & 78 \\
\hline
\end{tabular}

\section{$4 \quad$ Results}

\subsection{Experimental data from Beijing and Lhasa}

The flowrate of the slurry was measured under different concentrations and different cement-sand ratios in Beijing and Lhasa. The rheological parameters of the slurry were calculated and compared by using Equation (14). The results from both tests are shown in Tables 3 and 4.

Table 3 Test data of paste slurry by inclined pipe in Beijing

\begin{tabular}{|c|c|c|c|c|c|}
\hline $\begin{array}{c}\text { Concentration } \\
\text { (\%) }\end{array}$ & $\begin{array}{c}\text { Cement-sand } \\
\text { ratio }\end{array}$ & $\begin{array}{c}\text { Dip angle } \\
\left({ }^{\circ}\right)\end{array}$ & $\begin{array}{c}\text { Average } \\
\text { velocity }(\mathrm{m} / \mathrm{s})\end{array}$ & $\begin{array}{c}\text { Yield stress } \\
\qquad(\mathrm{Pa})\end{array}$ & $\begin{array}{c}\text { Plastic viscosity } \\
\text { (Pa.s) }\end{array}$ \\
\hline \multirow{2}{*}{70} & \multirow{2}{*}{$1: 4$} & $8.50^{\circ}$ & 1.66 & \multirow{2}{*}{15.78} & \multirow{2}{*}{0.03} \\
\hline & & $11.50^{\circ}$ & 1.95 & & \\
\hline \multirow{2}{*}{72} & \multirow{2}{*}{ 1:6 } & $8.50^{\circ}$ & 1.16 & \multirow{2}{*}{20.30} & \multirow{2}{*}{0.05} \\
\hline & & $11.50^{\circ}$ & 1.46 & & \\
\hline \multirow{2}{*}{74} & \multirow{2}{*}{$1: 25$} & $8.50^{\circ}$ & 0.25 & \multirow{2}{*}{34.09} & \multirow{2}{*}{0.15} \\
\hline & & $11.50^{\circ}$ & 0.48 & & \\
\hline \multirow{2}{*}{76} & \multirow{2}{*}{$1: 8$} & $8.50^{\circ}$ & 0.07 & \multirow{2}{*}{37.54} & \multirow{2}{*}{0.30} \\
\hline & & $11.50^{\circ}$ & 0.08 & & \\
\hline \multirow{2}{*}{78} & \multirow{2}{*}{$1: 12$} & $8.50^{\circ}$ & 0.05 & \multirow{2}{*}{49.82} & \multirow{2}{*}{0.35} \\
\hline & & $11.50^{\circ}$ & 0.07 & & \\
\hline
\end{tabular}

Table 4 Test data of paste slurry by inclined pipe in Lhasa

\begin{tabular}{|c|c|c|c|c|c|}
\hline $\begin{array}{c}\text { Concentration } \\
(\%)\end{array}$ & $\begin{array}{c}\text { Cement-sand } \\
\text { ratio }\end{array}$ & $\begin{array}{c}\text { Dip angle } \\
\left({ }^{\circ}\right)\end{array}$ & $\begin{array}{c}\text { Average } \\
\text { velocity }(\mathrm{m} / \mathrm{s})\end{array}$ & $\begin{array}{l}\text { Yield stress } \\
\text { (Pa) }\end{array}$ & $\begin{array}{c}\text { Plastic viscosity } \\
\text { (Pa.s) }\end{array}$ \\
\hline \multirow{2}{*}{70} & \multirow{2}{*}{$1: 4$} & $8.50^{\circ}$ & 1.58 & \multirow{2}{*}{15.20} & \multirow{2}{*}{0.04} \\
\hline & & $11.50^{\circ}$ & 1.86 & & \\
\hline \multirow{2}{*}{72} & \multirow{2}{*}{$1: 6$} & $8.50^{\circ}$ & 1.10 & \multirow{2}{*}{20.37} & \multirow{2}{*}{0.07} \\
\hline & & $11.50^{\circ}$ & 1.38 & & \\
\hline \multirow{2}{*}{74} & \multirow{2}{*}{$1: 25$} & $8.50^{\circ}$ & 0.20 & \multirow{2}{*}{33.90} & \multirow{2}{*}{0.18} \\
\hline & & $11.50^{\circ}$ & 0.46 & & \\
\hline \multirow{2}{*}{76} & \multirow{2}{*}{$1: 8$} & $8.50^{\circ}$ & 0.04 & \multirow{2}{*}{37.49} & \multirow{2}{*}{0.38} \\
\hline & & $11.50^{\circ}$ & 0.05 & & \\
\hline \multirow{2}{*}{78} & \multirow{2}{*}{$1: 12$} & $8.50^{\circ}$ & 0.03 & \multirow{2}{*}{49.94} & \multirow{2}{*}{0.39} \\
\hline & & $11.50^{\circ}$ & 0.04 & & \\
\hline
\end{tabular}




\subsection{Analysis of influencing factors of plastic viscosity}

The data analysis was carried out according to the rheological parameters measured in Lhasa. The quadratic polynomial regression equation of the relationship between the plastic viscosity, concentration and cementsand ratio was established. The results are shown by Equation (16). The correlation coefficient of the fitting equation is $R=0.9988$, and the significant level $p=0.0134<0.05$.

$$
y_{2}=10.5047-0.3254 x_{1}+0.3900 x_{2}+0.002499 x_{1}{ }^{2}
$$

Where:

$$
\begin{aligned}
& y_{2}=\text { Plastic viscosity of the slurry; } \\
& x_{1} \quad=\text { Concentration of the slurry; } \\
& x_{2} \quad=\text { Cement-sand ratio; }
\end{aligned}
$$

In the regression equation of the plastic viscosity, the correlation coefficient of the two factors are $r 1=0.9708$ and $\mathrm{r} 2=0.2855$. Therefore, the concentration of the slurry $\left(x_{1}\right)$ has a greater effect than the cement-sand ratio $\left(x_{2}\right)$ on the plastic viscosity. $x_{1}$ shows in the form of a linear term in the regression equation, but $x_{2}$ does not. So the effect needs to be analyzed by the path coefficient.

Table 5 Path coefficient of plastic viscosity related-factors

\begin{tabular}{ccccc}
\hline Factor & Direct effect & $\mathbf{x}_{\mathbf{1}}$ & $\mathbf{x}_{\mathbf{2}}$ & $\mathbf{x}_{\mathbf{1}} * \mathbf{x}_{\mathbf{1}}$ \\
\hline $\mathrm{x}_{1}$ & -6.9695 & - & 0.0181 & 7.9231 \\
$\mathrm{x}_{2}$ & 0.2130 & -0.5923 & - & 0.6649 \\
$\mathrm{x}_{1} * \mathrm{x}_{1}$ & 7.9241 & -6.9695 & 0.0179 & - \\
\hline
\end{tabular}

According to Table 5, the increase of concentration $\left(x_{1}\right)$ will lead to the decrease of the $x_{1}$ value and the increase of the $x_{12}$ value in the regression equation. The direct path coefficient of $x_{1}$ is positive $\left(P_{1}=-6.9695\right)$ with a direct negative effect and the direct path coefficient of $x_{12}$ is negative $\left(P_{11}=7.9231\right)$ with a direct positive effect. The interactive effect of the slurry concentration and the cement-sand ratio on the plastic viscosity of the slurry is shown in Figure 4.

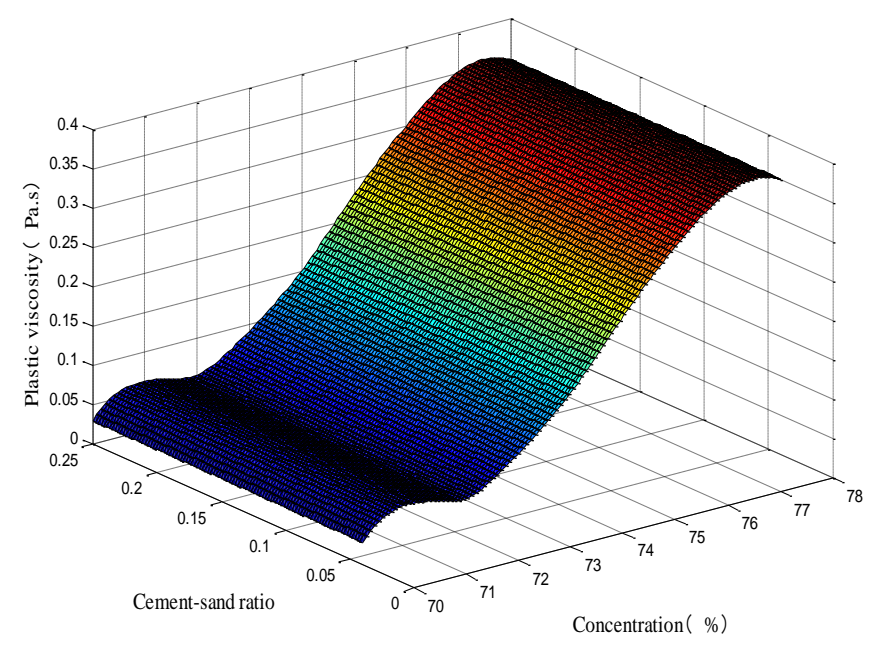

Figure 4 Response surface map of the concentration and the cement-sand ratio effect on plastic viscosity

According to Figure 4, the increase of the concentration and the cement-sand ratio leads to an increase of the plastic viscosity. At the same concentration, the color change is not obvious along the axial direction of the cement-sand ratio. But at the same cement-sand ratio, the color change is obvious along the axial 
direction of the concentration. It can be concluded that the influence of concentration is much greater than that of the cement-sand ratio.

\subsection{The effect of low atmospheric pressure on the yield stress of the slurry}

The data in Figure 5 show the comparison of yield stress between Lhasa and Beijing.

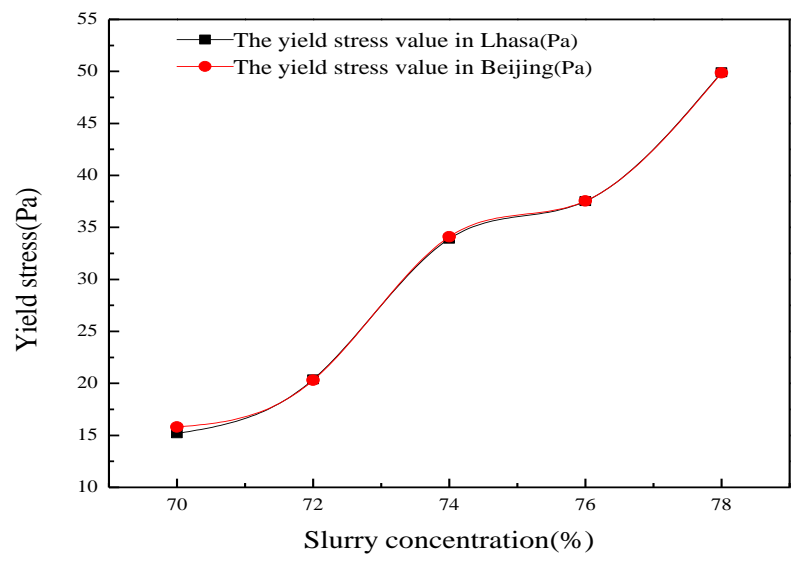

Figure 5 The comparison of slurry yield stress value in Lhasa and Beijing

Because of the less obvious differences in the yield stress value of the paste slurry between the two places, the effect of atmospheric pressure on yield stress is illustrated by the combination of the difference table. The results are shown in Table 6.

Table 6 Yield stress in Lhasa and Beijing compared

\begin{tabular}{ccccc}
\hline $\begin{array}{c}\text { Concentration } \\
\text { (\%) }\end{array}$ & $\begin{array}{c}\text { Lhasa value } \\
\mathbf{( P a )}\end{array}$ & $\begin{array}{c}\text { Beijing value } \\
(\mathbf{P a})\end{array}$ & $\begin{array}{c}\text { Lhasa value minus } \\
\text { Beijing value }\end{array}$ & $\begin{array}{c}\text { | Lhasa value minus Beijing } \\
\text { value | /Beijing value×100\% }\end{array}$ \\
\hline 70 & 15.2 & 15.8 & 0.60 & 3.80 \\
72 & 20.37 & 20.31 & 0.06 & 0.56 \\
74 & 33.9 & 34.09 & 0.19 & 0.30 \\
76 & 37.51 & 37.55 & 0.05 & 0.13 \\
78 & 49.92 & 49.86 & 0.06 & 0.12 \\
\hline
\end{tabular}

Figure 5 and Table 6 show that the yield stresses in Lhasa and Beijing are basically consistent. The effect of the variation of atmospheric pressure on yield stress can be disregarded although there are likely to be some experimental errors. With the increase of slurry concentration from 70 to $78 \%$, the difference of the yield stress values in the two places gradually decreases.

\subsection{The effect of low atmospheric pressure on plastic viscosity}

The data in Figure 6 and Table 7 compare the plastic viscosities of Lhasa and Beijing. 


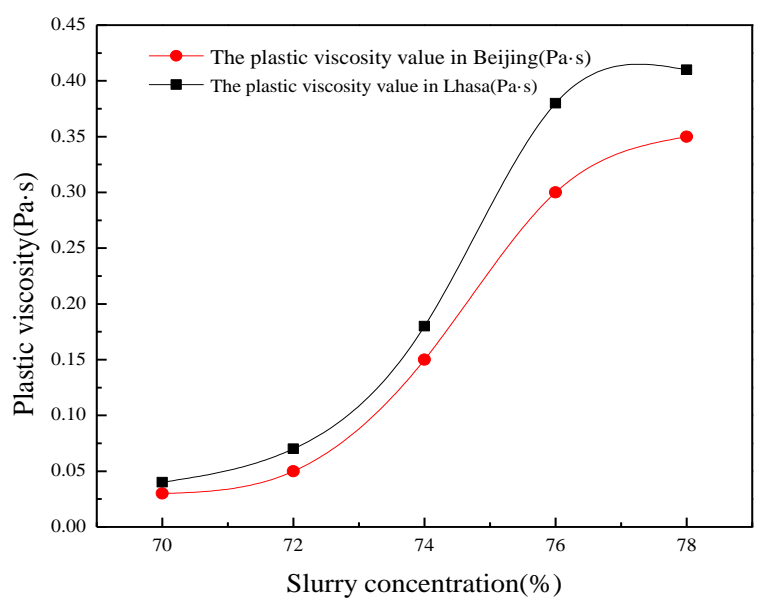

Figure 6 Slurry plastic viscosity value in Lhasa and Beijing compared

Table 7 Plastic viscosity in Lhasa and Beijing compared

\begin{tabular}{ccccc}
\hline $\begin{array}{c}\text { Concentratio } \\
(\%)\end{array}$ & $\begin{array}{c}\text { Lhasa value } \\
(\mathbf{P a})\end{array}$ & $\begin{array}{c}\text { Beijing value } \\
(\mathbf{P a})\end{array}$ & $\begin{array}{c}\text { Lhasa value minus } \\
\text { Beijing value }\end{array}$ & $\begin{array}{c}\text { | Lhasa value munus Beijing } \\
\text { value | / Beijing value×100\% }\end{array}$ \\
\hline 70 & 0.04 & 0.03 & 0.01 & 25.0 \\
72 & 0.07 & 0.05 & 0.02 & 28.6 \\
74 & 0.18 & 0.15 & 0.03 & 11.8 \\
76 & 0.38 & 0.30 & 0.08 & 21.0 \\
78 & 0.39 & 0.35 & 0.04 & 10.3 \\
\hline
\end{tabular}

With the concentration range of $70 \sim 78 \%$, the plastic viscosity measured in Lhasa is always greater than that measured in Beijing. In the range of the $70 \sim 76 \%$, the difference of plastic viscosity measured in Lhasa and Beijing respectively increases, but the influence ratio of the viscosity has a downward trend in general, decreasing from $25.0 \%$ with a concentration of 70 to $21.0 \%$ with a concentration of $76 \%$. The difference value reaches its maximum with a concentration of $77 \%$, and then has a downward trend as concentration increases. Finally, when the slurry concentration reaches $78 \%$, the difference decreases to $0.04 \mathrm{~Pa}$, and the influence ratio of the viscosity decreases to $10.3 \%$.

\subsection{The effect of low atmospheric pressure on the flow rate}

The angle of the inclined pipe is adjusted and the average flow rate of the slurry is calculated by combining the Equation (15) both at 8.5 and $11.5^{\circ}$. The results are shown in Figure 7. 


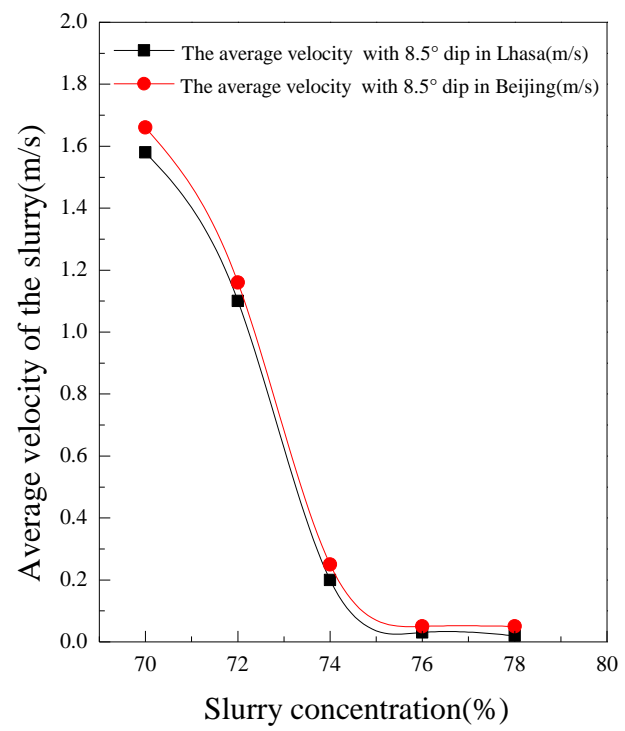

(a)

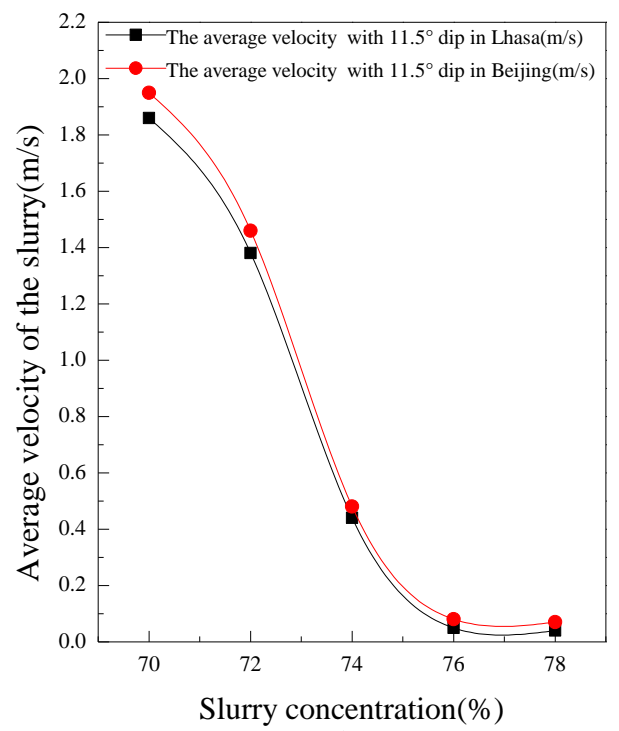

(b)

Figure 7 Comparison of the average flow rate in Lhasa and Beijing under two different angles; (a) $8.5^{\circ}$; (b) $11.5^{\circ}$

According to Figure 7, the flow rate of the paste slurry decreases with the increase of concentration at 8.5 and $11.5^{\circ}$ and the downward trend of Figure $7(\mathrm{a})$ is consistent with Figure $7(\mathrm{~b})$. In the range of $70 \sim 74 \%$, the flow rate of the paste slurry decreases sharply with the increase of concentration, while in the range of $74 \sim 78 \%$, the flow rate decreases slowly with the increase of concentration. Especially in the range of 76 78\%, the flow rate is stable below $0.1 \mathrm{~m} / \mathrm{s}$. Figure 7 shows that the average flow rate of the slurry in Beijing is always greater than that in Lhasa with different concentrations, and it also demonstrates that the flow characteristics of the paste slurry in high altitude areas is lower than that in plain areas.

\section{$5 \quad$ Conclusions}

An inclined pipe device is convenient and accurate in measuring the rheological parameters of paste slurry and ensuring more stable experimental results.

The paste slurry shows the structure flow pattern in the flow process. Its rheological parameters can be calculated by the Bingham model combined with the hydraulic formula of the paste slurry.

By regression analysis, it can be concluded that the increase of concentration and cement-sand ratio can raise the plastic viscosity of paste slurry, but the influence of concentration is far greater than that of the cement-sand ratio.

The relationship model between atmospheric pressure and flow characteristics of the paste slurry is established, which shows the flow characteristics of paste slurry can be changed by the effect of the atmospheric pressure on the viscosity of the slurry. The plastic viscosity of the paste slurry increases with the decrease of atmospheric pressure both in Lhasa and Beijing, and the plastic viscosity of the slurry measured in Lhasa is greater than that in Beijing under the same experimental conditions. The average flow rate of the slurry in Beijing is always greater than that in Lhasa both at 8.5 and $11.5^{\circ}$.

The low pressure of high altitude conditions makes the flow rate lower and can even cause a plugging accident. Therefore, the paste pipeline transport should take the local atmospheric pressure into account and take measures to avoid its impact on underground filling operations. 


\section{Acknowledgements}

The research was supported by National Natural Science Foundation of China, approval no. 51374034, 51374035 and 51304011 and National Science and Technology Support Program in 12th Five-Year, approval no. 2012BAB08B02. We offer special thanks to Feng Rui, a researcher at Experiment Center of School of Civil and Resources Engineering for valuable assistance provided. We have been also helped by Fengwei Wang, from the Jiama Copper Mine.

\section{References}

Bair, S., Winer, W.O. 1990, 'The high shear stress rheology of liquid lubricants at pressures of 2 to $200 \mathrm{MPa}$ ', Journal of Tribology. vol. 112 , no. 2, pp. 246-252.

Belem, T., Benzaazoua, M. 2004, 'An overview on the use of paste backfill technology as a ground support method in cut-and-fill mines', in Villaescusa and Potvin (Eds.), Proceedings of the 5th Int. Symp. Ground support in Mining and Underground Construction, pp. 8-30.

Belem, T., Benzaazoua, M. 2008, 'Design and application of underground mine paste backfill technology', Geotechnical and Geological Engineering. 2, vol. 26, no. 2, pp. 147-174.

Berrich, E., Aloui, F., Legrand, J. 2011, 'Inverse method for the dynamical analysis of wall shear rates using three-segment probes in parallel plate rheometer', Chemical engineering science. vol. 66, no. 17, pp. 3969-3978.

Clark, C.C., Vickery, J.D., Backer, R.R. 1995, 'Transport of total tailings paste backfill: results of full-scale pipe test loop pumping tests. US Department of the Interior', Bureau of Mines.

Dzuy, N.Q., Boger, D.V. 1983, 'Yield stress measurement for concentrated suspensions', Journal of Rheology, vol. 27, no. 4, pp. 321-349.

Gillies, R.G., Sun, R., Sanders, R.S. 2007, 'Lowered expectations: the impact of yield stress on sand transport in laminar, non-Newtonian slurry flows', Journal of the South African Institute of Mining and Metallurgy, vol. 107, no. 6, pp. 351-358.

Hirai, N., Eyring, H. 1959, 'Bulk viscosity of polymeric systems', Journal of Polymer Science, vol. 37, no. 131, pp. 51-70.

Hogarth, W.L., Parlange, J.Y., Rose, C.W., Fuentes, C., Haverkamp, R., Walter, M. T. 2005, 'Interpolation between Darcy-Weisbach and Darcy for laminar and turbulent flows', Advances in water resources, vol. 28, no. 10, pp. 1028-1031.

Huang, Y.C., Sun, H.H. 2003, 'Experimental study on the rheological characteristic of paste-like slurry with tailings as aggregate', Mental Mine, no. 6, pp. 8-10.

Jewell, R.J., Fourie, A.B. 2006, in R.J. Jewell and A.B. Fourie (eds), Paste and Thickened Tailings - A Guide, 2nd edition, Australian Centre for Geomechanics, Perth, Australia, pp. 25-37.

Karasu, S., Toker, O.S., Yilmaz, M.T., Karaman, S., Dertli, E. 2015, 'Thermal loop test to determine structural changes and thermal stability of creamed honey: Rheological characterization', Journal of Food Engineering, vol. 150, pp. 90-98.

Liu, T.Y. 2001, 'Application of filling mining technology', Beijing: Metallurgical Industry Press, pp. 45-46.

Liu, X.H., Wu A.X., Wang, H.J., Jiao, H.Z, Liu, S.Z., Wang, S.Y. 2014, 'Experimental study on thixotropic properties of unclassified-tailings paste slurry', Journal of Wuhan University of Technology (Transportation Science and Engineering), vol. 23, no. 2, pp. 539-541.

Meng, F.Y. 2011, 'Hydrodynamics and Fluid Machinery', Higher Education Press, Beijing, pp. 51-57.

Nasir, O., Fall, M. 2009, 'Modeling the heat development in hydrating CPB structures', Computers and Geotechnics, vol. 36, no. 7, pp. 1207-1218.

Rawlins, C.A., Phillips, H.R. 2001, 'Reduction of mine heat loads', Proceedings of the $7^{\text {th }}$ international mine ventilation congress, pp. 381-389.

Wallevik, J.E. 2009, 'Rheological properties of cement paste: thixotropic behavior and structural breakdown', Cement and Concrete Research, vol. 39, no. 1, pp. 14-29.

Wang, H.W. 2010, 'Optimum material proportion and transportation parameter of multiphase complex paste backfill', Central South University, Changsha. 
Wang, S.Y., Wu, A.X., Yin, S.H., Han, B., Wang, H.J. 2015, 'Influence factors of pressure loss in pipeline transportation of paste slurry', Chinese Journal of Engineering, no. 1, pp. 7-12.

Wang, W., Zhu, H., Kee, D.D., Khismatullin, D. 2010, 'Numerical investigation of the reduction of wall-slip effects for yield stress fluids in a double concentric cylinder rheometer with slotted rotor', Journal of Rheology, vol. 54, no. 6, pp. 1267-1283.

Wang, X., Zhao, X.Y., Qu, Y.Y., Hu W.W., Chen, J., Wu, M. 2008, 'Experimental research on particle characteristics and rheological properties of high concentrationed mud', Metal Mine, vol. 1, pp. 107-109.

Wang, X.M., Li, J.X., Xiao, Z.Z., Xiao, W.G. 2004, 'Rheological properties of tailing paste slurry', Journal of Central South University of Technology, vol. 11, no. 1, pp. 75-79.

Wu, A.X., Jiao, H.Z., Wang, H.J., Li H., Yi, H.B., Liu, X.H., Liu, S.Z. 2013, 'Yield stress measurements and optimization of paste tailings', Journal of Central South University: Science and Technology, vol. 44, no. 8, pp. 3370-3376. 